Research Paper

\title{
Combined Cancer Photothermal-Chemotherapy Based on Doxorubicin/Gold Nanorod-Loaded Polymersomes
}

\author{
JinFeng Liao ${ }^{1}$, WenTing Li1, JinRong Peng ${ }^{1}$, Qian Yang1, ${ }^{1}$ He Li², YuQuan Wei ${ }^{1}$, XiaoNing Zhang 3 , ZhiYong \\ Qian $^{1, \square}$ \\ 1. State Key Laboratory of Biotherapy/Collaborative Innovation Center for Biotherapy, West China Hospital, Sichuan University, \\ Chengdu, 610041, P.R. China \\ 2. School of Medical and Life Sciences, University of Jinan, Jinan 250022, PR China \\ 3. School of Medicine, Tsinghua University, Beijing, 100084, China
}

$\triangle$ Corresponding author: Tel: +86-28-85164063, Fax: +86-28-85164060, E-mail: anderson-qian@163.com or zhiyongqian@scu.edu.cn.

(C) Ivyspring International Publisher. This is an open-access article distributed under the terms of the Creative Commons License (http:/ / creativecommons.org/ licenses/by-nc-nd/3.0/). Reproduction is permitted for personal, noncommercial use, provided that the article is in whole, unmodified, and properly cited.

Received: 2014.10.05; Accepted: 2014.12.15; Published: 2015.01.20

\begin{abstract}
Gold nanorods (GNRs) are well known in photothermal therapy based on near-infrared (NIR) laser absorption of the longitudinal plasmon band. Herein, we developed an effective stimulus system -- GNRs and doxorubicin co-loaded polymersomes (P-GNRs-DOX) -- to facilitate co-therapy of photothermal and chemotherapy. DOX can be triggered to release once the polymersomes are corrupted under local hyperthermic condition of GNRs induced by NIR laser irradiation. Also, the cytotoxicity of GNRs caused by the residual cetyltrimethylacmmonium bromide (CTAB) was reduced by shielding the polymersomes. The GNRs-loaded polymersomes (P-GNRs) can be efficiently taken up by the tumor cells. The distribution of the nanomaterial was imaged by IR-820 and quantitatively analyzed by ICP-AES. We studied the ablation of tumor cells in vitro and in vivo, and found that co-therapy offers significantly improved therapeutic efficacy (tumors were eliminated without regrowth.) compared with chemotherapy or photothermal therapy alone. By TUNEL immunofluorescent staining of tumors after NIR laser irradiation, we found that the co-therapy showed more apoptotic tumor cells than the other groups. Furthermore, the toxicity study by pathologic examination of the heart tissues demonstrated a lower systematic toxicity of P-GNRs-DOX than free DOX. Thus, the chemo-photothermal treatment based on polymersomes loaded with DOX and GNRs is a useful strategy for maximizing the therapeutic efficacy and minimizing the dosage-related side effects in the treatment of solid tumors.
\end{abstract}

Key words: polymersomes; gold nanorod; NIR; photothermal therapy; chemotherapy.

\section{Introduction}

Photothermal therapy is an attractive method for treating solid tumors in a minimally invasive manner[1,2]. This therapy utilizes the conversion of absorbed near-infrared (NIR) light to focus heat. NIR light is poorly absorbed by normal biological tissues; it can provide deep-tissue penetration with high spatial precision, targeting the tumor environment[3]. To date, several gold nanostructures including gold nanoparticles[4-8], nanocage[9] nanoclusters[10], nanostars[11], nanocubes[12], nanoshells[13-15], and nanorods (GNRs)[16-18] have been used in NIR photothermal therapy. Studies of photothermal therapy have revealed some disadvantages to these approaches. Specifically, the formation of gold nanoshells and cages is relatively complex, involving a complicated gold-coating process. However, GNRs lack such drawbacks. They can be easily synthesized using a seed-mediated route and have the adjustable aspect ratio to achieve NIR light absorption. Meanwhile, large-scale synthesis is efficient and GNRs have 
colloidal stability. Even so, GNRs have limited clinical use due to the cytotoxicity caused by the residual CTAB, which served as a template during GNR synthesis process. To reduce such cytotoxicity, polymers[19-23] are being widely used for surface modification of GNRs by electrostatic adsorption.

Nanoparticles have been loaded into polymersomes for optimization of their properties[24,25], Hydrophobically modified maghemite nanoparticles were encapsulated within the membrane of poly(trimethylene carbonate)- $b$-poly( L-glutamic acid) (PTMC-b-PGA) block copolymer vesicles[26]. These magnetic vesicles exhibited a long-term colloidal stability and showed an important contrast enhancement in Magnetic Resonance Imaging with a particularly low (subnanomolar) detection limit. But to date, polymersomes made from monomethyl poly(ethylene glycol)-poly( $\varepsilon$-caprolactone) (mPEG-PCL) have not been used as a vehicle of GNRs to reduce cytotoxicity and enhance photothermal therapy. Polymersomes are spherical vesicles formed by the self-assembly of amphiphilic block copolymers with appropriate hydrophilic/hydrophobic ratio in aqueous environment[27]. Polymersomes can both encapsulate hydrophilic molecules within the aqueous interior and integrate hydrophobic molecules within the hydrophobic membrane[28,29]. The polymersomes made from $\mathrm{mPEG}$-PCL have a melting point in accord with the hyperthermia caused by the GNRs[30], which results in enhanced release of antitumor drug. Doxoru-

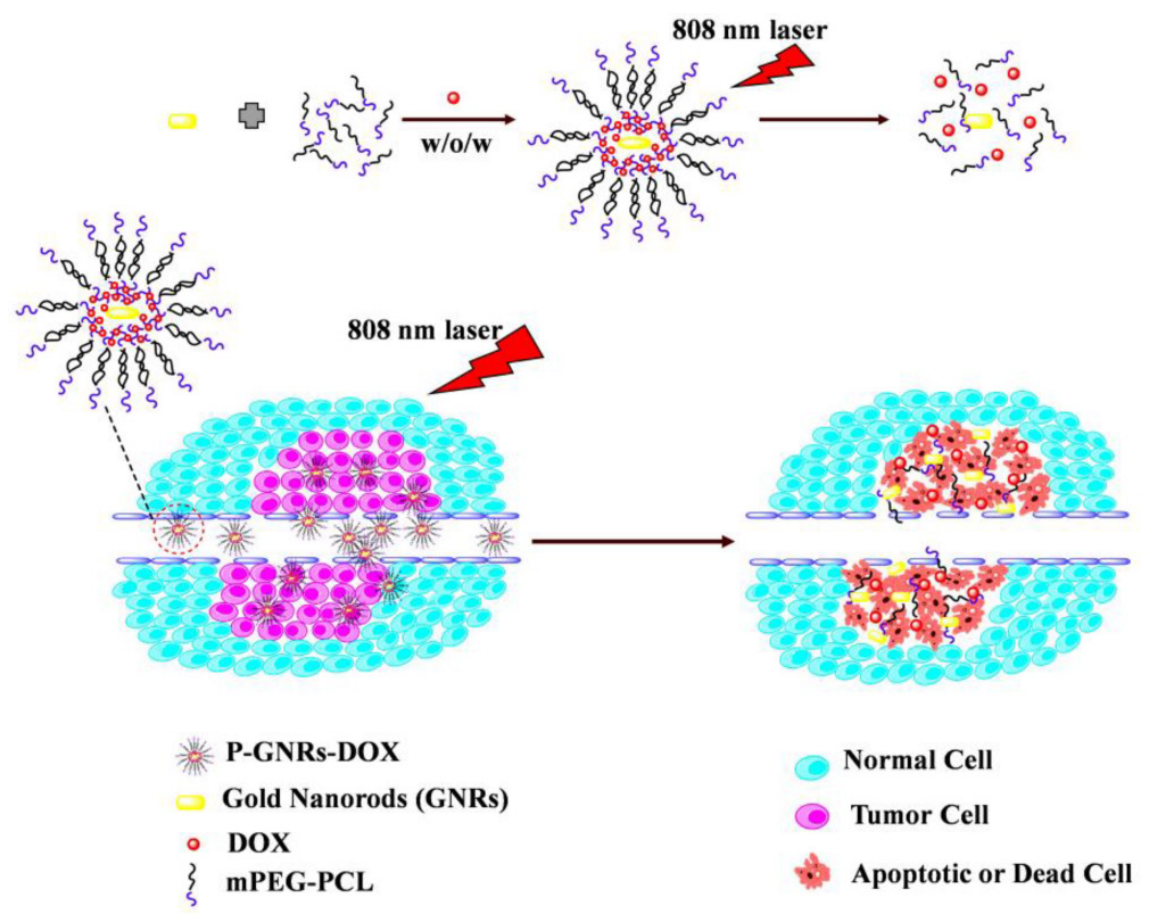

Figure 1. Schematic illustration of the preparation P-GNRs-DOX and the collapse of polymersomes after $808 \mathrm{~nm}$ laser irradiation. The co-therapy of photothermal and chemotherapy lead the tumor cells to dead or apoptosis. bicin (DOX) is an effective antitumor drug, but severe cardiotoxicity and bone marrow suppression limits dosing regimens that are sufficiently high to destroy cancer cells without damaging healthy tissue. Polymersomes have been used to encapsulate DOX to reduce such effects, but the overall chemotherapeutic efficacy was unsatisfactory[31]. Thus, more information about combination of chemotherapy and photothermal therapy to target tumor is warranted. To address this, advances in photothermal technology have yielded several synergistic therapies for cancer treatment. For example, GNR-capped magnetic core/mesoporous silica shell nanoellipsoids[32] and a mesoporous silica nanorattle-gold shell[13] have been applied to co-deliver GNRs and drug to the targeted tumor, enhancing overall therapeutic efficacy compared to single treatments of each therapeutic component alone. Xiao and co-workers[33] developed a self-assembled DNA-based platform co-loaded with DOX and GNRs. The platform selectively delivered DOX to target cells and effectively inhibited tumor growth via thermo-chemotherapy. One major limitation of this study was the local delivery strategy of intratumoral injection.

Herein, we fabricated NIR-stimulated polymersomes that can co-deliver GNRs and DOX for cancer therapy. As illustrated in Figure 1, the amphiphilic block copolymer mPEG-PCL with an appropriate hydrophilic/hydrophobic ratio self-assemble into polymersomes. DOX and GNRs can be co-loaded the polymersomes. Subsequent DOX release is triggered under local hyperthermic condition induced by NIR laser exposure. Heat from the GNRs not only promotes drug delivery into the tumor, but also increases the drug toxicity to tumor cells[34]. Finally, the tumor cells treated with co-therapy of photothermal and chemotherapy were all apoptotic or dead.

\section{Materials and Methods}

\section{Materials.}

Methylpolyethylene glycol (mPEG, $\mathrm{Mn}=5,000)$, $\varepsilon$-caprolactone $(\varepsilon-\mathrm{CL}, \mathrm{Mn}=114)$, atannous octoate $\left[\mathrm{Sn}(\mathrm{Oct})_{2}\right]$, sodium borohydride $\left(\mathrm{NaBH}_{4}\right)$, $\mathrm{L}(+)$-ascorbic acid (Vc), IR-820 were purchased from Sigma-Aldrich Corp. (St. Louis, MO). Acid tetrachloroaurate (III) trihy- 
drate $\left(\mathrm{HAuCl}_{4} \cdot 3 \mathrm{H}_{2} \mathrm{O}\right)$ was purchased from Sinopharm Chemical Reagent Co. Ltd. (Shanghai, China). CTAB was obtained from China national medicines Co., Ltd (Beijing, China). Doxorubicin chloride (doxorubicin, DOX) was obtained from Zhejiang Hisun Pharmaceutical Company (Zhejiang, China). Deionized water $(18.2 \mathrm{M} \Omega \mathrm{cm})$ was used to prepare all of the aqueous solutions. All chemicals were analytical grade and used without further purification. TUNEL assays were performed using the Flurescein FragEL DNA fragmentation detection kit (Calbiochem, catalog number QIA39, Merck, Germany). Female BALB/c mice (4-6 weeks old) were purchased from Beijing HFK Bioscience Co., Ltd. They were housed at a temperature of $20-22{ }^{\circ} \mathrm{C}$, relative humidity of $50-60 \%$, with $12 \mathrm{~h}$ light-dark cycles. They were also provided with free access to food and water. All studies involving mice were approved by the institute's animal care and use committee.

\section{Synthesis and Characterization of MPEG-PCL Copolymer.}

mPEG-PCL $(5,000-30,000)$ copolymer with the designed molecular weight of 35,000 was synthesized by ring-opening polymerization of $\varepsilon-\mathrm{CL}$ and $\mathrm{mPEG}$ $(\mathrm{Mn}=5,000)$ catalyzed by $\mathrm{Sn}(\mathrm{Oct})_{2}$ at $135^{\circ} \mathrm{C}$ according to a previously published method $[35,36]$. The obtained mPEG-PCL copolymer was purified and vacuum dried.

\section{Preparation of GNRs.}

GNRs were synthesized through a seed-mediated approach modified from a method described by Murphy and coworkers[37]. Briefly, gold seed particles were prepared by adding $100 \mu \mathrm{L}$ of 24 $\mathrm{mM} \mathrm{HAuCl} \cdot 3 \mathrm{H}_{2} \mathrm{O}$ to $7.5 \mathrm{~mL}$ of $0.1 \mathrm{M} \mathrm{CTAB}$ with gentle mixing. Then, $600 \mu \mathrm{L}$ of freshly prepared, ice-cold $10 \mathrm{mM} \mathrm{NaBH}_{4}$ solution was added following by mixing for $2 \mathrm{~min}$. The brown-yellow seed solution was kept undisturbed at $25^{\circ} \mathrm{C}$ for $2 \mathrm{~h}$ before use.

Next, the gold nanorod growth solution was prepared, which consisted of $100 \mathrm{~mL}$ of $0.1 \mathrm{M} \mathrm{CTAB}$, $2.04 \mathrm{~mL}$ of $24 \mathrm{mM} \mathrm{HAuCl}_{4}, 2 \mathrm{~mL}$ of $0.5 \mathrm{M} \mathrm{H}_{2} \mathrm{SO}_{4}, 0.9$ $\mathrm{mL}$ of $0.01 \mathrm{M} \mathrm{AgNO}_{3}$ and $0.8 \mathrm{~mL}$ of $0.1 \mathrm{M} \mathrm{L}$-ascorbic acid. A seed solution $(240 \mu \mathrm{L})$ was added to the above-mentioned growth solution to initiate the growth of the GNRs. After $12 \mathrm{~h}$, the GNRs were purified by centrifugation $(12,000 \mathrm{rpm}, 10 \mathrm{~min})$. The precipitates were collected and redispersed in deionized water.

\section{Preparation of DOX and GNRs Co-loaded Polymersomes.}

DOX and GNRs co-loaded polymersomes were prepared using a double emulsion method. Typically,
$0.5 \mathrm{~mL}$ water solution containing DOX and GNRs were added dropwise into $7.5 \mathrm{~mL}$ solution of $15 \mathrm{mg}$ mPEG-PCL under sonication on ice. This primary emulsion was emulsified by sonication on ice in 15 $\mathrm{mL} 0.1 \%$ PVA $\mathrm{pH}=7.4$ phosphate-buffered saline (PBS). Subsequently, the resulting water-in-oil-in-water $(\mathrm{w} / \mathrm{o} / \mathrm{w})$ double emulsion was diluted by mixing with $50 \mathrm{~mL}$ of $0.1 \%$ PVA $\mathrm{pH}=7.4$ PBS solution under vigorous stirring in the dark overnight to evaporate the dichloromethane solvent. DOX and GNRs co-loaded polymersomes were then centrifuged to discard the free drug and residual GNRs, and redispersed in different cryoprotectant solutions for lyophilization prior to use. Transmission electron microscopy (TEM) micrographs were obtained on a Tecnai G ${ }^{2}$ F20 S-TWIN TEM (FEI Co., Oregon, USA) at an accelerating voltage of $120 \mathrm{kV}$. The samples were prepared by dropping them on a copper grid followed by staining with phosphotungstic acid $(1 \%)$ and dried at room temperature. Particle sizes and zeta potentials were determined using a Zetasizer Nano-ZS from Malvern Instruments (Zetasizer nano ZSP, Malvern, England). The amount of GNRs loaded into polymersomes was measured using an inductively coupled plasma-atomic emission spectrometer (ICP-AES, SPECTRO ARCOS, Spectro, Germany). Polymersomes were lyophilized using a Wizard 2.0 vacuum freeze drying machine (VirTis, SP Scientific, New York, USA). The photo-stability of P-GNRs was optically characterized by UV-vis extinction spectroscopy.

\section{NIR Laser Stimulated Release of DOX.}

The release of DOX from polymersomes was measured using a dialysis method. Briefly, $5 \mathrm{mg}$ of P-GNRs-DOX was redispersed in $1 \mathrm{~mL}$ PBS $(10 \mathrm{mM}$, $\mathrm{pH}=7.4$ ), then placed in a dialysis bag (molecular weight cutoff $=8,000-14,000$ ) and sealed. Dialysis fluids consisted of $10 \mathrm{~mL} \mathrm{pH}=5.0,6.0$ and 7.4 PBS. DOX release was measured over time, and fresh PBS was replaced at each time point. At the same time points, samples that were/were not irradiated with the NIR laser (centered at $808 \mathrm{~nm}$, output power $=2.5$ $\mathrm{W} \mathrm{cm}^{-2}$ for $5 \mathrm{~min}$ ). DOX released from samples was measured by UV-vis.

\section{Bio-TEM and Fluorescence Microscopy Images of Cells Uptake.}

C26 cells were incubated in $10 \mathrm{~mL}$ of Dulbecoo's modified Eagle's medium (DMEM) at a density of $5.0 \times 10^{6}$ cells. After $24 \mathrm{~h}$, growth medium was replaced with fresh DMEM containing $40 \mu \mathrm{g} / \mathrm{mL}$ P-GNRs and then the $\mathrm{C} 26$ cells were incubated for $2 \mathrm{~h}$ at $37^{\circ} \mathrm{C}$. The cells were collected by centrifugation at $1,500 \mathrm{rpm}$ for $5 \mathrm{~min}$. After removing supernatant solution, the cells 
were fixed by adding $2.5 \%$ glutaraldehyde solution. The fixed cells were successively stained with $2 \%$ osmium tetroxide and $0.5 \%$ uranyl acetate. The sample was embedded and processed for ultrathin sectioning. Ultrathin sections were cut and observed by TEM. Besides, the localization of DOX was directly observed by a fluorescent microscope (Leica, Germany) and photomicrographs were taken.

\section{In Vitro Cytotoxicity Test.}

The cytotoxicity of P-GNRs was measured using $3 \mathrm{~T} 3$ cells and C26 tumor cells. Cells were seeded in 96-well plates $\left(5.0 \times 10^{3}\right.$ cells per well) in $100 \mu \mathrm{L}$ DMEM medium and were incubated at $37{ }^{\circ} \mathrm{C}$ for an additional $24 \mathrm{~h}$. Then, cells were exposed to various concentrations of GNR-loaded polymersomes for $24 \mathrm{~h}$, and cell viability of cells was measured by the MTT method.

\section{Cell Viability after Photothermal Therapy.}

For cell viability measurements, C26 cells were plated into 96-well plates $\left(5.0 \times 10^{3}\right.$ per well) and allowed to adhere prior to addition of varying concentrations of free DOX, P-DOX, and P-GNRs-DOX. The cells treated with P-GNRs-DOX about $4 \mathrm{~h}$ for uptake before laser irradiation. Then cells were/were not irradiated with an $808 \mathrm{~nm}$ NIR laser (power density $=$ $2.5 \mathrm{~W} \mathrm{~cm}^{-2}$ for $5 \mathrm{~min}$ ). Next, cells were incubated for 24 $\mathrm{h}$ at $37^{\circ} \mathrm{C}$. Cell viability was measured using the MTT assay. The data reported represent the means of triplicate measurements.

\section{Biodistribution.}

To investigate the biodistribution of P-GNRs, we loaded a NIR imaging agent (IR-820, is a cyanine dye to be used as a contrast agent in tumor cell imaging) into the polymersomes (named as P-GNRs-820). NIR fluorescence images were obtained using an IVIS Lumina (Perkin-Elmer) at 1, 4, and $24 \mathrm{~h}$ after injection. The mice were sacrificed at $24 \mathrm{~h}$ after injection of the nanomaterials. The major organs including tumors were collected and were completely lysed in digesting solutions $\left(\mathrm{HNO}_{3}: \mathrm{HCl}: \mathrm{HClO}_{4}=3: 1: 2\right.$ by volume). The samples were heated at $200{ }^{\circ} \mathrm{C}$ for $2 \mathrm{~h}$. After cooling down to temperature, each of the resulting solution was then diluted by deionized water to $5 \mathrm{~mL}$, and subsequently analyzed by ICP-AES to determine the total amount of $\mathrm{Au}$ in each measured organ.

\section{IR Thermal Imaging.}

Mice bearing C26 tumors treated with P-GNRs-DOX were irradiated with the $808 \mathrm{~nm}$ laser at power density of $2.5 \mathrm{~W} \mathrm{~cm}^{2}$ for $5 \mathrm{~min}$, and simultaneously imaged by a Fluke Ti32 Infrared (IR) thermal camera (Infrared Cameras, USA).

\section{Photothermal Therapy of Balb/c Mice Bearing C26 Solid Tumors.}

All animals were handled in accordance with the guidelines of the Animal Care and Use Committee of the State key Laboratory of Biotherapy. To induce a solid tumor, C26 cells $\left(1.0 \times 10^{6}\right)$ were injected subcutaneously into the right rear flank area of female Balb/c mice ( 8 weeks). When the tumors grew to approximately $4 \mathrm{~mm}$ in diameter, the mice were divided into eight groups ( $n=16 /$ group). To compare the effect of photothermal ablation of the solid tumor, the mice were administered A) normal saline (NS, 200 $\mu \mathrm{L}$ ), B) normal saline with the laser (NS+laser, 200 $\mu \mathrm{L}), \mathrm{C})$ free DOX for 1 time $(5 \mathrm{mg} / \mathrm{kg}, 200 \mu \mathrm{L}), \mathrm{D})$ free DOX for 4 times $(5 \mathrm{mg} / \mathrm{kg}, 200 \mu \mathrm{L})$, E) P-DOX (5 $\mathrm{mg} / \mathrm{kg}, 200 \mu \mathrm{L}), \mathrm{F})$ P-GNRs (50 mg/kg, $200 \mu \mathrm{L}), \mathrm{G})$ P-GNRs with the laser $(50 \mathrm{mg} / \mathrm{kg}, 200 \mu \mathrm{L}), \mathrm{H})$ P-GNRs-DOX with the laser $(2.5 \mathrm{mg} / \mathrm{kg}, 200 \mu \mathrm{L}$, in terms of DOX) intravenously through tail veins. Next, tumor regions of the laser-treated groups were irradiated with NIR laser $\left(2.5 \mathrm{~W} \mathrm{~cm}^{-2}, 5 \mathrm{~min}\right)$ at $24 \mathrm{~h}$ post-injection. Then after $12 \mathrm{~h}$ three mice from each group were sacrificed, and tumors were removed. A TUNEL assay was performed according to the manufacturer's recommended protocol for "tissue cryosections". Tumors of the remaining mice in the eight groups were measured with a digital caliper every other day and calculated as volume $=$ (tumor length) $\times(\text { tumor width })^{2} / 2$. Relative tumor volumes were calculated as $\mathrm{V} / \mathrm{V}_{0}\left(\mathrm{~V}_{0}=\right.$ tumor volume when treatment was initiated). The mice were also photographed using a digital camera at the time of tumor size measurement. Finally, after 14 days, hearts from three mice in each group were removed for H\&E histological processing and analysis.

\section{Results and Discussion}

\section{The Characterizatin of Hybrid Polymersomes.}

The mPEG-PCL copolymer was synthesized by ring-opening polymerization of $\varepsilon$-CL by mPEG5000. Supplementary Material: Figure S1 shows that mPEG-PCL was successfully synthesized. The bare polymersomes (diameter $\approx 175 \mathrm{~nm}$ ) were prepared as a carrier for GNRs and DOX using a double emulsion method (Figure $2 \mathrm{~A}$ ). The thickness of polymersome membrane was about $12 \mathrm{~nm}$ (Figure $2 \mathrm{~B}$ ), related to the length of the amphiphilic block copolymer, which can be explained as molecular packing parameter[38-40]. To confirm that mPEG-PCL formed vesicles, we placed Nile red (a hydrophobic dye) in the oil phase during the preparation of polymersomes and observed the $\mathrm{w} / \mathrm{o} / \mathrm{w}$ emulsion using a CLSM. Confocal image depicted Nile red-labeled polymersomes (Figure $3 \mathrm{~A}$ ). Nile red is hydrophobic and the fluo- 
rescence intensity contributed around the particle border (Figure $3 \mathrm{~B}$ ), suggesting the encapsulation of Nile red in the membrane of the polymersomes. Thus, the result confirms the bilayer structure of polymersomes. For effective cancer cell imaging and photothermal therapy, GNRs (aspect ratio of $\sim 4$ ) with a longitudinal absorption band at $\sim 808 \mathrm{~nm}$ were synthesized using the seed-mediated growth method (Figure $2 \mathrm{C}$ inset). GNRs were loaded into polymersomes by adding GNRs to the internal water phase of polymersomes (Figure $2 \mathrm{C}$ ). The amount of GNRs (Au content) loaded in polymersomes deter- mined by ICP-AES was $\sim 3.6 \mathrm{wt} \%$. The zeta-potential of GNRs stabilized in a CTAB solution had highly positively charged surface states $(+37.8 \mathrm{mV})$, but GNRs-loaded polymersomes $(-5.1 \mathrm{mV})$ had surface charge similar to those of the nanocarriers themselves $(-6.6 \mathrm{mV})$, suggesting that GNRs were shielded once inside the polymersomes. On the other hand, absorption peaks of the P-GNRs had a modest redshift compared with that of GNRs (Figure $4 \mathrm{~A}$ ). The redshift may be attributed to the presence of GNRs in the polymersomes.
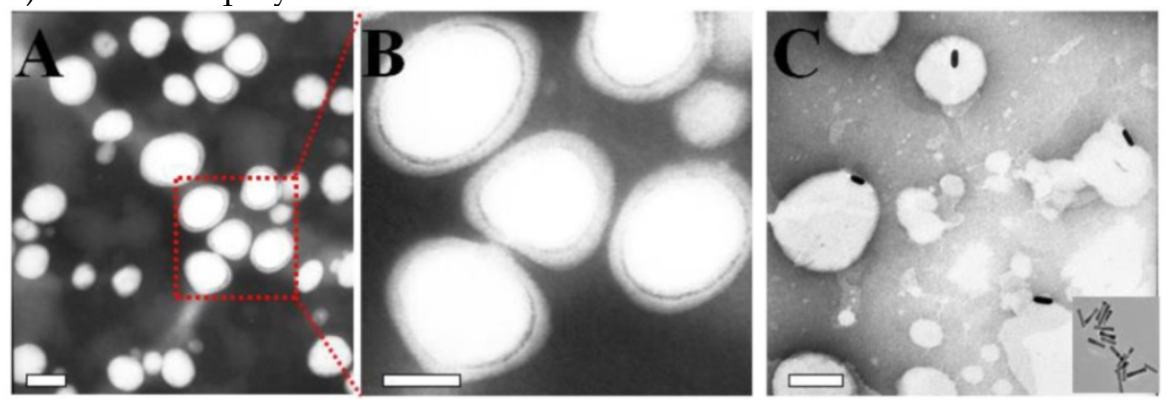

Figure 2. TEM images of A) polymersomes, B) the magnification of the polymersomes, C) P-GNRs (Inset: GNRs). The scale bar is $100 \mathrm{~nm}$.

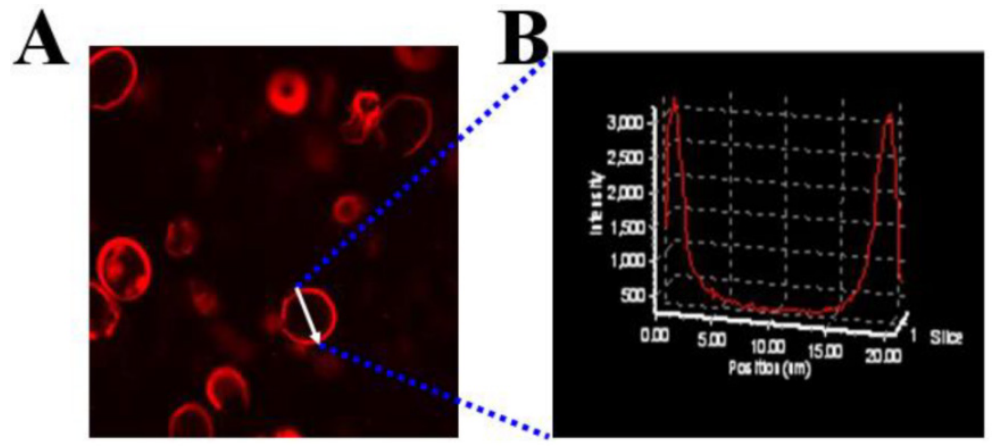

Figure 3. A) CLSM image of Nile red encapsulated the membrane of polymersomes, B) Fluorescence intensity across the Nile red-labeled polymersome.
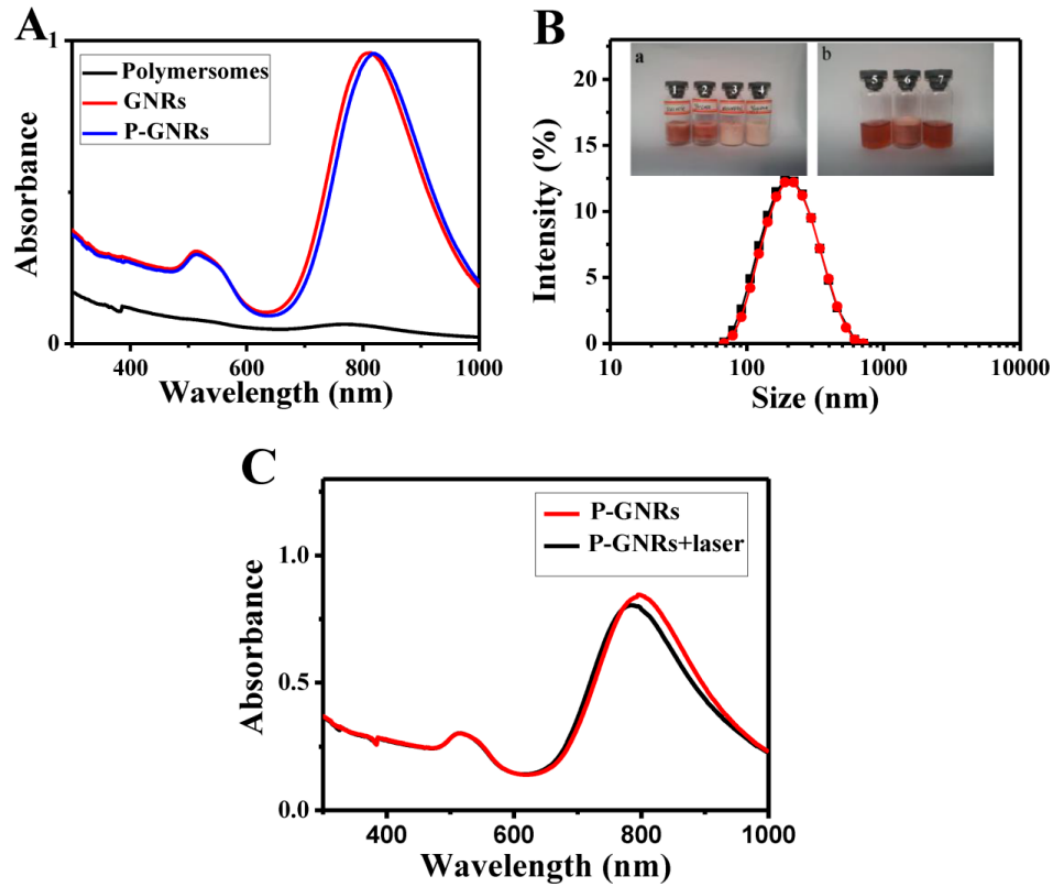

Figure 4. A) UV-vis absorption spectra of polymersomes, GNRs and P-GNRs. B) The particle size distribution spectrum of P-GNRs-DOX (black line: prior to lyophilization; red line: after lyophilization). Inset: a) Photographs of lyophilized P-GNRs-DOX with different lyoprotectants (1. sucrose; 2. glucose; 3. mannitol; 4. glycine). b) The redispersion of P-GNRs-DOX with sucrose (5. P-GNRs-DOX; 6. lyophilized P-GNRs-DOX with sucrose; 7. redispersion of P-GNRs-DOX with sucrose). C) Measured UV-vis extinction spectra of P-GNRs before and after laser irradiation. 
The P-GNRs-DOX can be stable for 1 week at 4 ${ }^{\circ} \mathrm{C}$, but not too long. To maintain the physicochemical properties of polymersomes for a long time, it's necessary to lyophilize P-GNRs-DOX with lyoprotectants[41]. Lyophilized P-GNRs-DOX at its final volume showed an intact shape occupying the same volume as the original frozen mass with different lyoprotectants (sucrose, glucose, mannitol or glycine) used at 5 wt \% concentration. However, mannitol and glycine converted the P-GNRs-DOX to a turbid color (Figure 4 $\mathrm{B}$, inset). Among these lyoprotectants, the desirable hydrodynamic particle size and post-reconstruction distribution was achieved with sucrose (Figure 4 B). The mean hydrodynamic particle size of P-GNRs-DOX was $\sim 208 \mathrm{~nm}$ and $\sim 210 \mathrm{~nm}$ before and after being lyophilized with sucrose, respectively.

The photo-stability of P-GNRs was optically characterized by UV-vis extinction spectroscopy (Figure $4 \mathrm{C}$ ). The longitudinal plasmon peak is a good indicator for shape changes of GNRs, because the peak position strongly depends on the aspect ratio[42, 43]. Indeed, after the aqueous P-GNRs solution irradiation for $5 \mathrm{~min}$ (power output $=2.5 \mathrm{w} \mathrm{cm}^{-2}$ ), the
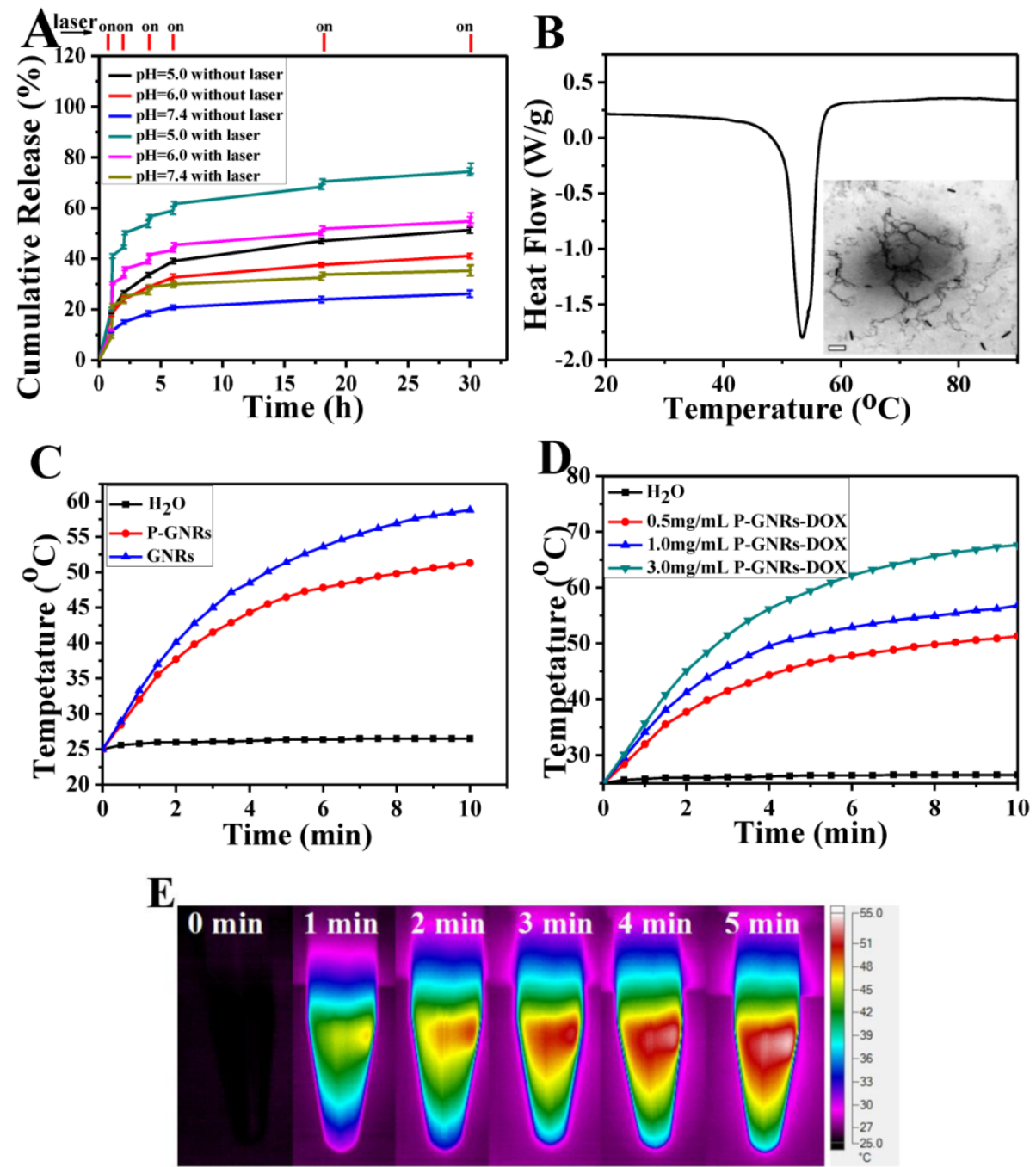

longitudinal plasmon peak was a bit blue shift $(\sim 8$ $\mathrm{nm})$. The photo-stability of P-GNRs in our study is good enough for photothermal therapy.

\section{Drug Loading Capacity and NIR Laser Stimu- lated Release of DOX.}

Drugs were loaded into polymersomes similar to the method used for GNRs. According to the standard curve of absorption of DOX (490 nm, the standard curve $\mathrm{A}=18.84 \mathrm{C}+0.0005)$, we calculated that the drug loading capacity of the polymersomes reached $19.7 \mathrm{wt}$ $\%$ and the entrapped efficiency was about $84.3 \%$. The release of DOX from P-GNRs-DOX could be readily controlled with NIR laser irradiation and manipulations of $\mathrm{pH}$ (Figure $5 \mathrm{~A}$ ). Within 5 min after NIR laser irradiation (output $=2.5 \mathrm{~W} \mathrm{~cm}^{-2}$ ), the cumulative drug release almost doubled compared to no irradiation treatment. DOX release was significantly reduced during the subsequent hour of incubation after irradiation was removed. Similar results were observed when the laser treatment protocol was repeated in other treatment cycles. Investigation of DOX release after incubations at various $\mathrm{pH}$ revealed that at lower $\mathrm{pH}$, more DOX was released. A sample at $\mathrm{pH}$ of 5.0 released almost $70 \%$ of the encapsulated DOX in $30 \mathrm{~h}$. Because the extracellular tissues of tumors and intracellular lysosomes have a $\mathrm{pH}$ of approximately 5.0[44], this microenvironment can support increased DOX release. Enhanced DOX release triggered by NIR laser may be attributed to the heat generated from the GNRs.

Figure 5. A) DOX-release profiles in the presence and absence of NIR laser under different $\mathrm{pH}$ conditions. B) DSC curve of mPEG-PCL. Inset: TEM of P-GNRs-DOX after NIR laser irradiation (scale bar $=50 \mathrm{~nm}$ ). C) Heating curves of pure water, P-GNRs-DOX and GNRs (14 $\mu \mathrm{g}$ Au mL-1). D) Different concentrations of P-GNRs-DOX $(0.5 \mathrm{mg} \mathrm{mL}-1$, P-GNRs-DOX contained $14 \mu \mathrm{g}$ Au $\mathrm{mL}^{-1}$ ) under NIR laser irradiation (power density $=2.5 \mathrm{~W}$ $\mathrm{cm}^{-2}$ ). E) Infrared thermal imaging of P-GNRs-DOX $\left(1.0 \mathrm{mg} \mathrm{mL}^{-1}\right.$, contained $28 \mu \mathrm{g}$ Au $\mathrm{mL}^{-1}$ ) under $2.5 \mathrm{~W} \mathrm{~cm}^{-2}$ irradiation by 808 $\mathrm{nm}$ laser a $\mathrm{t}$ different time. 


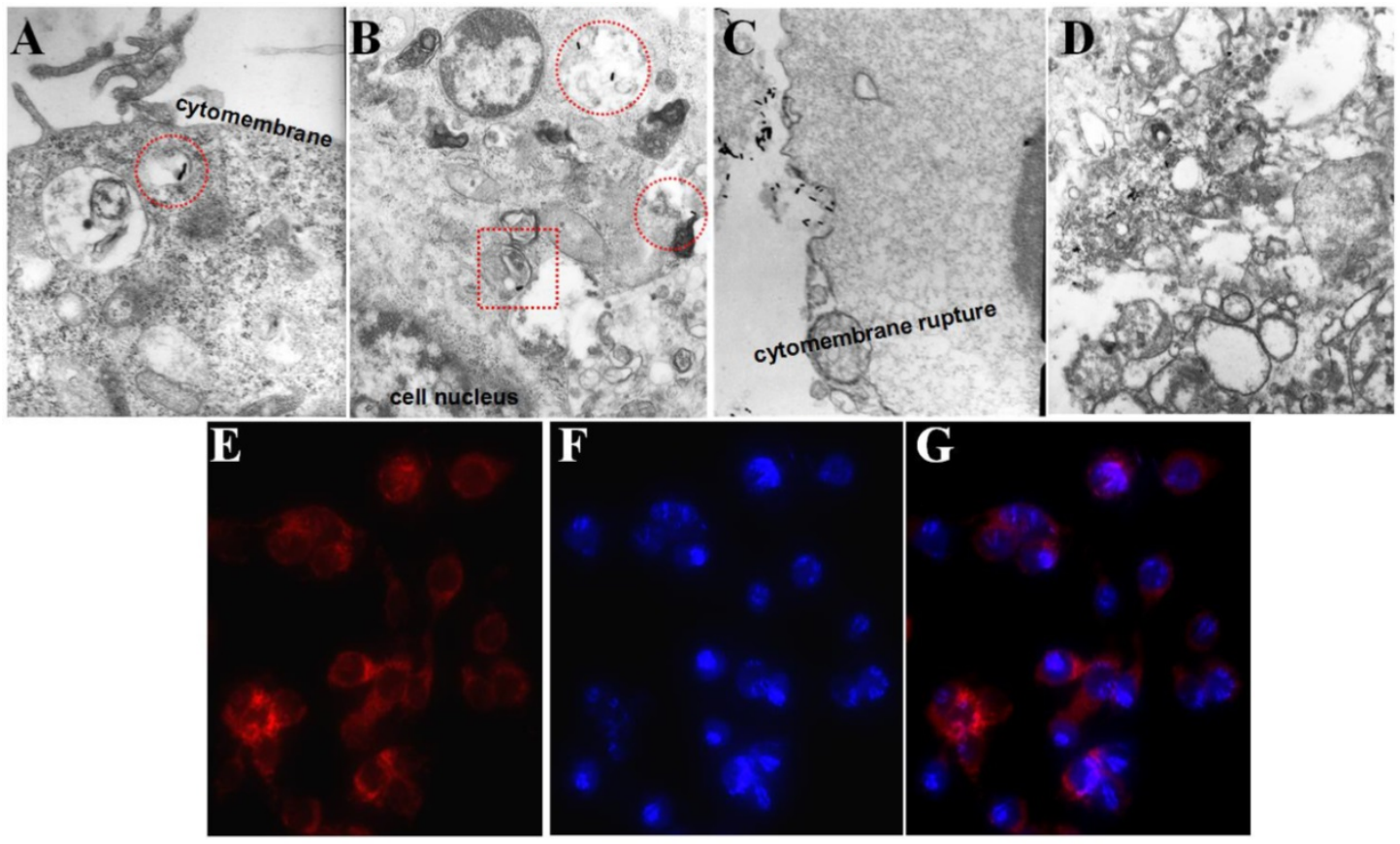

Figure 6. Selected bio-TEM images of A, B) P-GNRs and C, D) GNRs uptake by C26 tumor cells. Fluorescent microscopic images of C26 tumor cells after incubated with P-GNRs-DOX for $2 \mathrm{~h}$ : E) red fluorescence shows the location of DOX, F) blue fluorescence shows the nuclei stained with DAPI and G) merge; Images were acquired at $400 \times$ magnification.

When the aqueous solutions of GNRs and P-GNRs-DOX, both $14 \mu \mathrm{g}$ Au mL-1, were exposed to the NIR laser ( $2.5 \mathrm{~W} \mathrm{~cm}^{-2}$ for $5 \mathrm{~min}$ ), the temperature was increased to $58.8{ }^{\circ} \mathrm{C}$ and $51.3{ }^{\circ} \mathrm{C}$, respectively (Figure 5 C). In P-GNRs-DOX, The heat was absorbed partly by polymersomes, which induced the corruption of the polymersomes because the temperature was higher than the melting point of mPEG-PCL (Figure 5 B). In comparison, no significant temperature change was observed when $\mathrm{H}_{2} \mathrm{O}$ was exposed to the NIR laser. The more P-GNRs-DOX contained in the medium, the higher temperature increased upon laser excitation (Figure $5 \mathrm{D}$ ). As shown in Figure $5 \mathrm{~F}$, $1.0 \mathrm{mg} \mathrm{mL}^{-1}$ P-GNRs-DOX (contained $28 \mu \mathrm{g} \mathrm{Au} \mathrm{mL}^{-1}$ ) was monitored by an infrared thermal camera within $5 \mathrm{~min}$. Thus, the additional heat mediated by GNRs in the presence of NIR laser may be responsible for NIR laser-triggered release of DOX[45,46].

\section{Bio-TEM and Fluorescence Microscopy Images of Cells Uptake.}

Cellular uptake of P-GNRs was visualized with bio-TEM and fluorescent microscopy. As marked by the red circle in Figure $6 \mathrm{~A}$ and B, the P-GNRs were phagocytized by $\mathrm{C} 26$ tumor cells and trapped into the intracellular endosomes, and then, escape from the endosomes into the cytoplasm (red square in Figure 6 B). On the other hand, the tumor cells happened to dead when incubated with $8 \mu \mathrm{g} / \mathrm{mL}$ GNRs (Figure 6 $\mathrm{C}$ and $\mathrm{D})$. The cytomembranes were ruptured and the structure of the organelles (like mitochondrion and golgiosome) was destroyed by CTAB. This result suggested the polymersomes can reduce the cytotoxicity of the GNRs and help efficiently take up by cells. Microscopy images of C26 cells incubated with P-GNRs-DOX for $2 \mathrm{~h}$ were obtained, and then specially marked with DAPI for nuclei staining with blue fluorescence (Figure $6 \mathrm{E}$ ). Red fluorescence comes from DOX (Figure $6 \mathrm{~F}$ ), indicative of the location of P-GNRs-DOX (Figure $6 \mathrm{G}$ ), which agreed with the result of bio-TEM.

\section{In Vitro Cytotoxicity Test and Tumor Cells Viability after Photothermal Therapy.}

Next, we studied dose dependency of biocompatibility and cell killing efficiency of the nanovehicle in vitro. As shown in Figure $7 \mathrm{~A}$, cell viability remained greater than $90 \%$ even at P-GNRs concentration of $500 \mu \mathrm{g} \mathrm{mL}^{-1}$ (for 3T3 cells) and $125 \mathrm{gg} \mathrm{mL}^{-1}$ (for C26 cells). Also, P-GNRs (up to $8.0 \mathrm{mg} \mathrm{mL}^{-1}$ ) did not induce hemolysis in vitro (Figure $7 \mathrm{~B}$ ). Then, the in vitro viability of $\mathrm{C} 26$ tumor cells was measured with free DOX, P-DOX, P-GNRs-DOX without irradiation, and P-GNRs-DOX with irradiation. As seen in Figure $8 \mathrm{C}$, dose-dependent cytotoxicity occurred in the six groups as shown. Approximately $56.35 \%$ and $57.48 \%$ of cells were killed by P-DOX and P-GNRs-DOX, respectively which was equivalent to DOX concentration $\left(10 \mu \mathrm{g} \mathrm{mL}^{-1}\right)$. However, free DOX was more toxic, killing $78.33 \%$ of cells at the same drug concentration. The decreased cytotoxicity with P-DOX and P-GNRs-DOX could be attributed to delayed DOX 
release inside cells. After NIR laser irradiation $(2.5 \mathrm{~W}$ $\mathrm{cm}^{-2}$ for $5 \mathrm{~min} /$ treatment), P-GNRs-DOX killed significantly more cancer cells $(73.22 \%)$ at an equivalent DOX concentration $\left(10 \mu \mathrm{g} \mathrm{mL}^{-1}\right)$. Greater cytotoxicity of P-GNRs-DOX compared with P-DOX primarily resulted from enhanced release of DOX upon NIR laser irradiation. The cell viability of P-DOX group or free DOX upon NIR irradiation have little different compared with the each group without laser irradiation, which indicates the absence of GNRs cannot lead to the enhanced tumor cell dead.
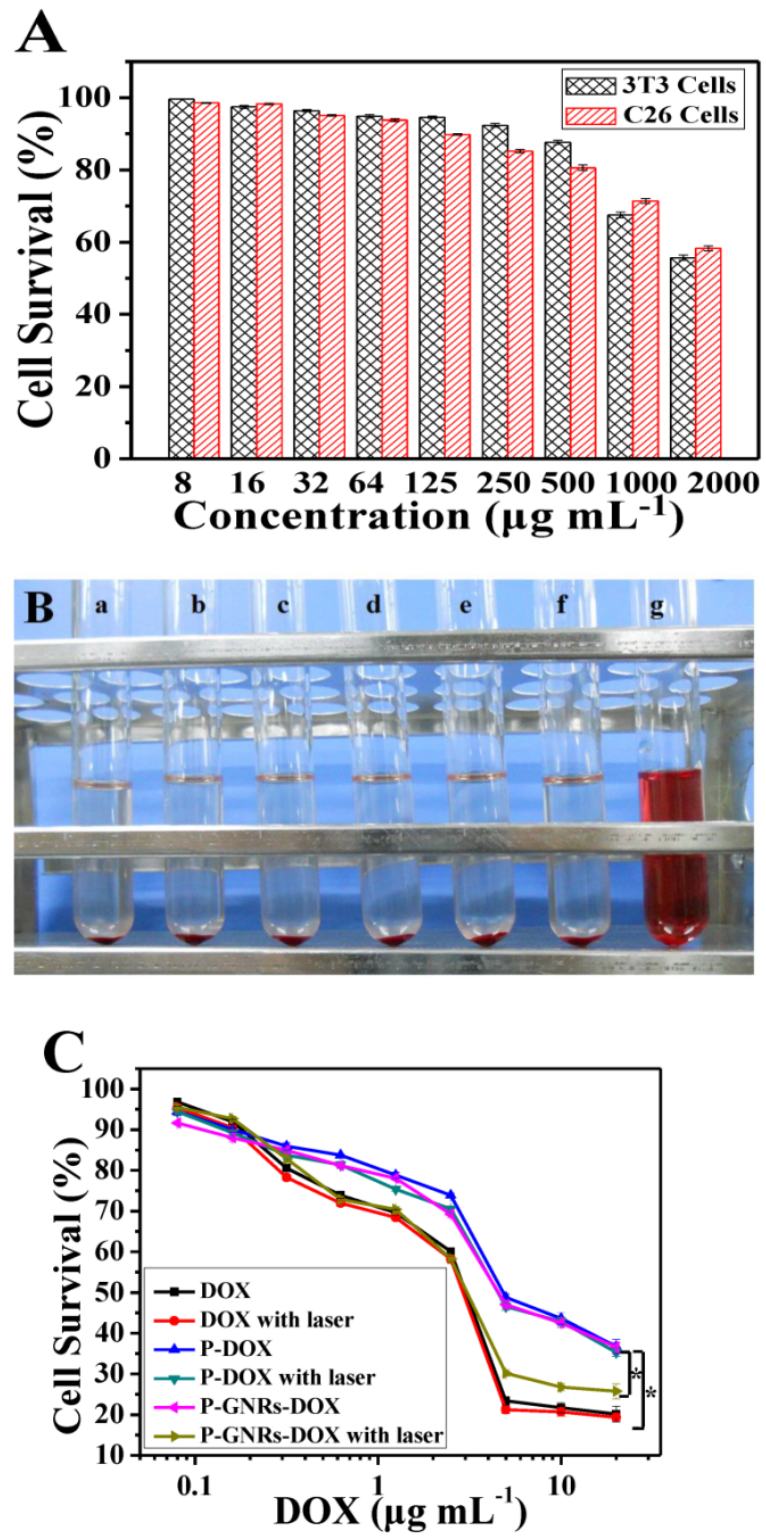

Figure 7. A) Relative viabilities of $3 T 3$ and $C 26$ cells after being incubated with various concentrations of P-GNRs for $24 \mathrm{~h}$. B) Hemolytic test on the P-GNRs. The concentration was a) $1.0 \mathrm{mg} \mathrm{mL}^{-1}$, b) $1.5 \mathrm{mg} \mathrm{mL}^{-1}$, c) $3.0 \mathrm{mg} \mathrm{mL}^{-1}$, d) $6.0 \mathrm{mg}$ $\mathrm{mL}^{-1}$, e) $12.0 \mathrm{mg} \mathrm{mL}^{-1}$; sample f was normal saline used as negative control, and sample $g$ was distilled water used as positive control. C) Relative viabilities of C26 tumor cells either not exposed to NIR light or irradiated with NIR light (2.5

$\mathrm{W} \mathrm{cm}^{-2}$ for $5 \mathrm{~min}$ per treatment, three treatments over $2 \mathrm{~h}$ ). Data are represented as mean $\pm \mathrm{SE}$ of six wells per group. ${ }^{*} \mathrm{P}<0.05$ by two-sample student's t-test.

\section{Biodistribution.}

To investigate the biodistribution of P-GNRs in major organs and the tumor, the P-GNRs-820 was intravenously injected through tail vein into mice bearing C26 tumors. NIR fluorescence images were obtained at 1, 4, and $24 \mathrm{~h}$ after injection, respectively (Figure $8 \mathrm{~A}$ ). Tumor sites showed higher fluorescence intensity at $24 \mathrm{~h}$, indicating the accumulation of the injected nanomaterials in the tumor sites with enhanced permeability and retention (EPR) effect. To analyze quantitatively the amount of GNRs, major organs including tumors were excised and lysed, and the gold content was determined by ICP-AES. As shown in Figure 8 B, GNRs had a decent tumor uptake of $7.94 \% \mathrm{ID} / \mathrm{g}$ at $24 \mathrm{~h}$. The accumulation of GNRs in the reticuloendothelial systems (RES) (such as liver, spleen) was high, which was in accordance with the result of NIR fluorescence image.

\section{IR Thermal Imaging.}

We further investigated the in vivo heating efficacy of P-GNRs-DOX in C26 tumor mice by tail injection of P-GNRs-DOX. At $24 \mathrm{~h}$ post-injection, the tumor was exposed to an $808 \mathrm{~nm}$ laser beam with power intensity of $2.5 \mathrm{~W} \mathrm{~cm}$. The red circle (the area above $43^{\circ} \mathrm{C}$ ) broadened with time, due to the gradual thermal accumulation and diffusion in the exposed region, and the stable temperature distribution was reached in about $5 \mathrm{~min}$. The temperature in exposed region reached $45{ }^{\circ} \mathrm{C}$ at $5 \mathrm{~min}$ (Figure 9), which was high enough to kill tumor in vivo[47]. Tumor cells undergo heat stress in the temperature resulting in activation of many intra and extracellular degradation mechanisms like protein denaturation, protein folding, aggregation and DNA cross linking[48]. While no significant temperature change was observed in the mice of control group. This demonstrates that P-GNRs-DOX is an efficient and potential agent for the in vivo co-therapy of photothermal and chemotherapy of tumor.

\section{Photothermal- and Chemo- Therapy of Balb/c Mice Bearing C26 Solid Tumors.}

Then, we conducted comparative efficacy studies in vivo. C26 tumor-bearing mice were divided into 8 groups and treated with the protocols summarized in the experimental section. Mice treated with NS, NS+laser and P-GNRs had a similar and rapid tumor growth (Figure $10 \mathrm{~A}$ ), indicating that laser irradiation only or P-GNRs did not affect tumor development. In addition to tumor growth, mouse weight in these three groups increased (Figure $10 \mathrm{~B}$ ). The P-DOX treated group had influenced the growth of tumor unobviously, so the body weight also increased along with the tumor growth. Mice received free DOX in- 
jections every other day for a total of 4 administrations had a rapid reduction in tumor volume, as well as body weight reduction, suggesting systemic toxicity of free DOX. As shown in Figure 11, free DOX injected once and 4 times had noticeable lesions in heart tissues as evidenced by H\&E staining. Tumors from P-GNRs+laser and P-GNRs-DOX+laser groups were exposed to an $808 \mathrm{~nm}$ laser $\left(2.5 \mathrm{~W} \mathrm{~cm}^{-2}, 5 \mathrm{~min}\right) 24$ $\mathrm{h}$ after injection. Tumors in the P-GNRs+laser group disappeared after 14 days, but $30 \%$ of the mice grew new tumors later, due to the incomplete ablation. Meanwhile, mice treated with P-GNRs-DOX+laser achieved total tumor ablation 2 days after NIR irradiation, and black scars were observed at the original tumor sites (Figure $10 \mathrm{D}$ ). P-GNRs-DOX+laser may be more ablative, causing tumor cell necrosis[4]. The black scars healed after seven days post-treatment; tumors did not reoccur, and no significant body weight changes were observed. Also, control mice had an average life span of 45-57 days, whereas mice in the P-GNRs-DOX+laser group were tumor-free after treatment and survived more than six months without a single death (Figure $10 \mathrm{C}$ ). H\&E histological analysis of heart tissues was also normal. From the immunofluorescent TUNEL staining assay of tumors (Figure 12), laser irradiation to the NS group had no effect on tumor cells. More apoptotic tumor cells were found in the P-GNRs-DOX+laser (apoptotic index $12.52 \pm 0.84 \%)$ and P-GNRs+laser groups (9.45 \pm $1.22 \%)$ than the other groups $(\mathrm{P}<0.01)$. The P-GNRs-DOX+laser group had more pronounced apoptotic induction than the P-GNRs+laser group, the apoptotic apoptotic index was increased in the P-GNRs-DOX+laser groups compared with P-GNRs+laser group was $1.33(\mathrm{P}<0.01)$. With the chemo- and photothermal- treatment, permanent irreversible DNA/RNA and protein damage can occur resulting in the elimination of tumor.
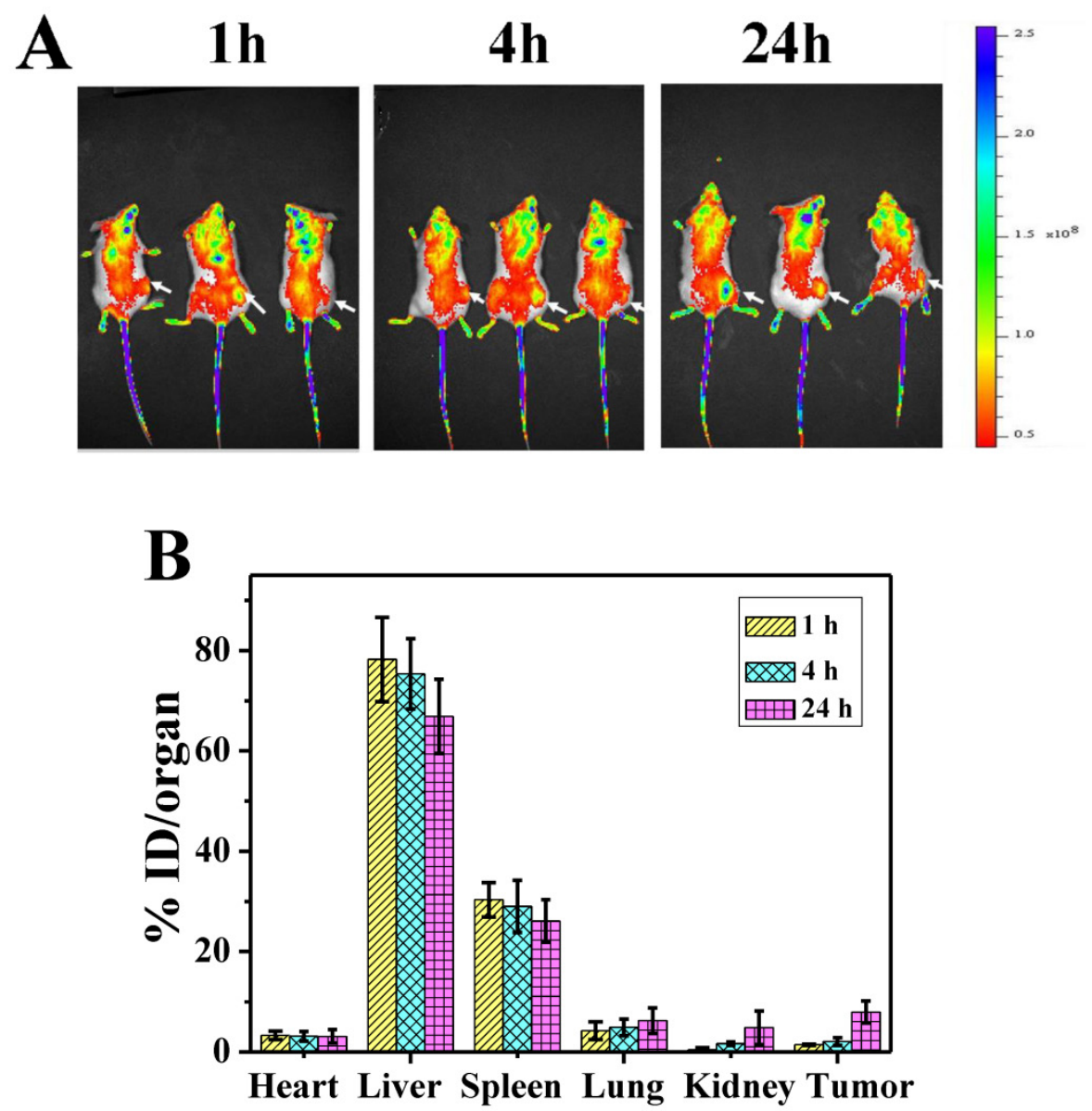

Figure 8. A) NIR fluorescence images of P-GNRs-820 treated mice were obtained $1 \mathrm{~h}, 4 \mathrm{~h}$, and $24 \mathrm{~h}$ after injection. The arrows indicate tumor sites. B) Biodistribution of P-GNRs in mice at $1 \mathrm{~h}, 4 \mathrm{~h}, 24 \mathrm{~h}$ after injection determined by ICP-AES measured of Au concentrations. Error bars were based on standard deviations (SD) of three mice per group. 


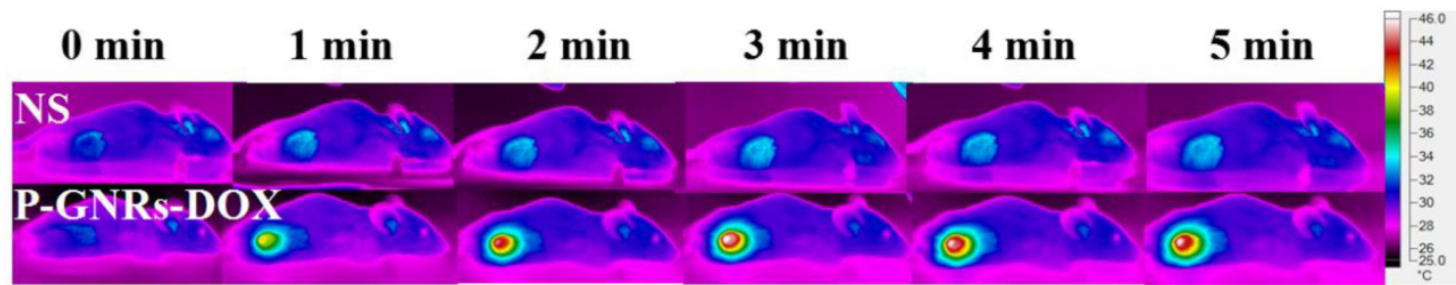

Figure 9. Infrared thermal imaging of tumor under the photothermal heating by $808 \mathrm{~nm}$ laser irradiation at A) $0 \mathrm{~min}$, B) $1 \mathrm{~min}$, C) $2 \mathrm{~min}$, D) $3 \mathrm{~min}$, E) $4 \mathrm{~min}$, F) $5 \mathrm{~min}$ in NS and P-GNRs-DOX injected mice under $2.5 \mathrm{~W} \mathrm{~cm}-2$ irradiation.
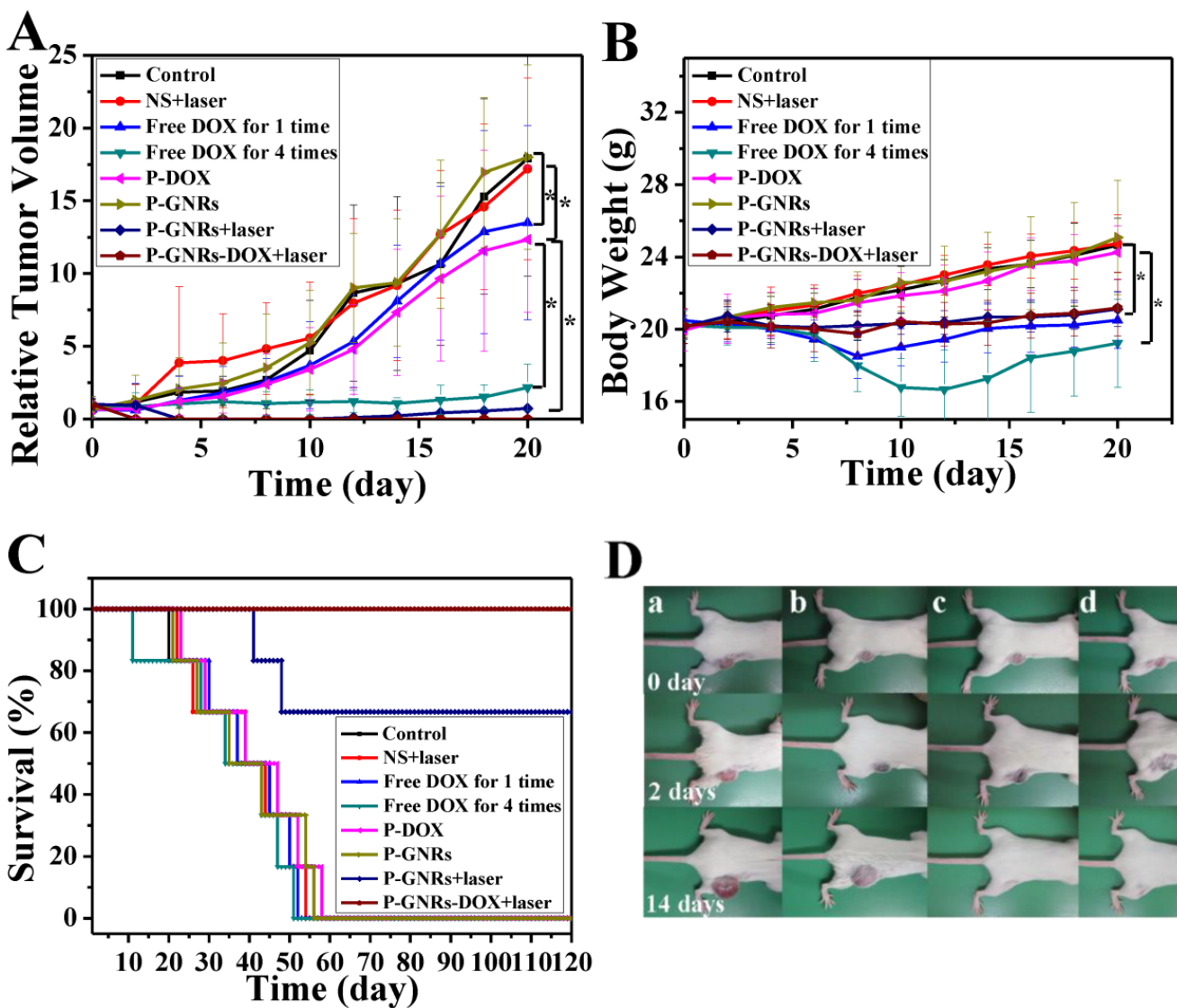

D

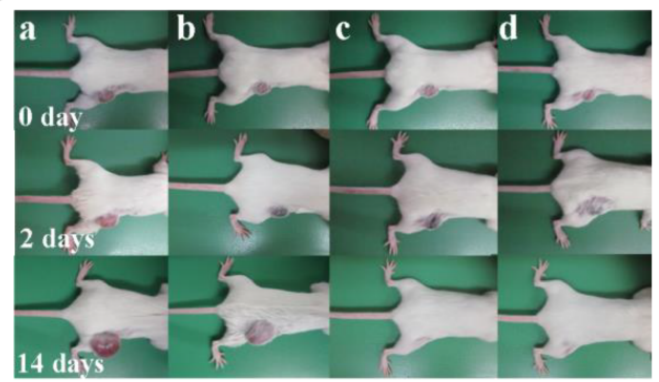

Time (day)

Figure 10. A) Tumor growth curves, B) Body weight of mice and C) Survival curves of mice bearing C26 tumors after various treatments as indicated. Data are represented as mean $\pm S E$ of ten mice per group. ${ }^{*} \mathrm{P}<0.05$ by two-sample student's $\mathrm{t}$-test. $\left.\mathrm{D}\right)$ Representative photos of mice bearing $\mathrm{C} 26$ tumors after a) NS treatment, b) NS+laser treatment, c) P-GNRs+laser treatment and d) P-GNRs-DOX+laser treatment for 0, 2 and 14 days.
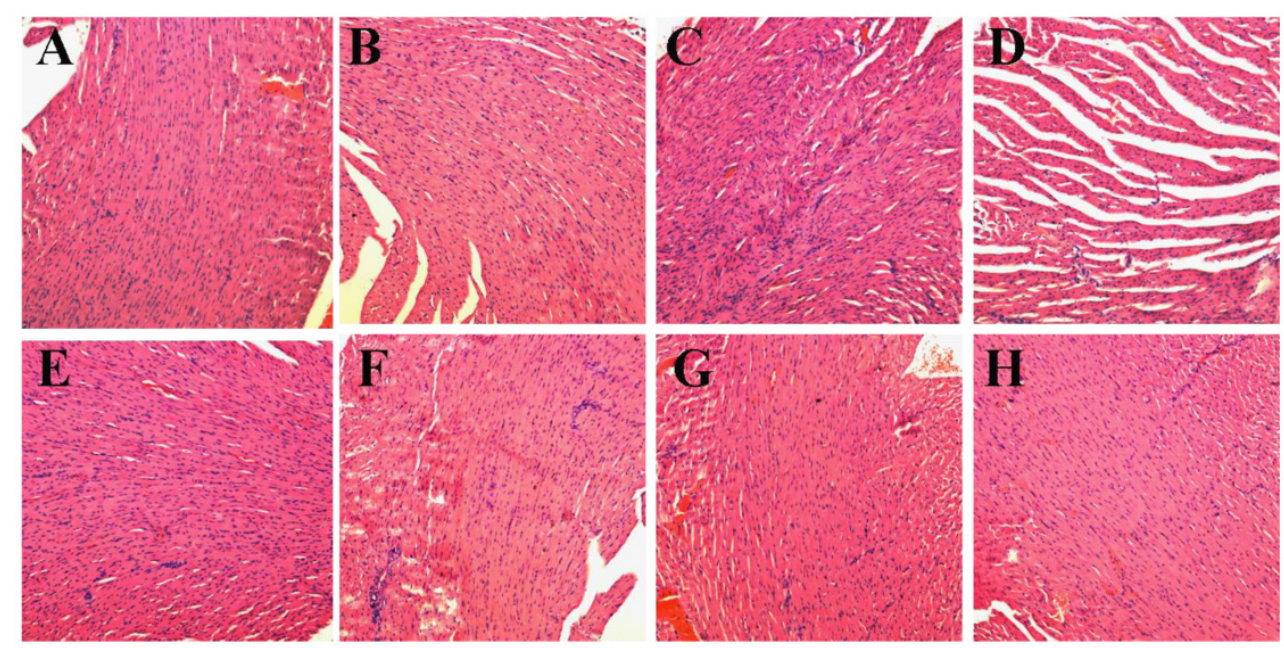

Figure 11. H\&E stained images of heart. Representative H\&E stained images of NS (A), NS+laser (B), free DOX for 1 time (C), free DOX for 4 times (D), P-DOX $(E)$, P-GNRs (F),P-GNRs+laser (G), and P-GNRs-DOX+laser $(H)$. Images were acquired at $400 \times$ magnification. 

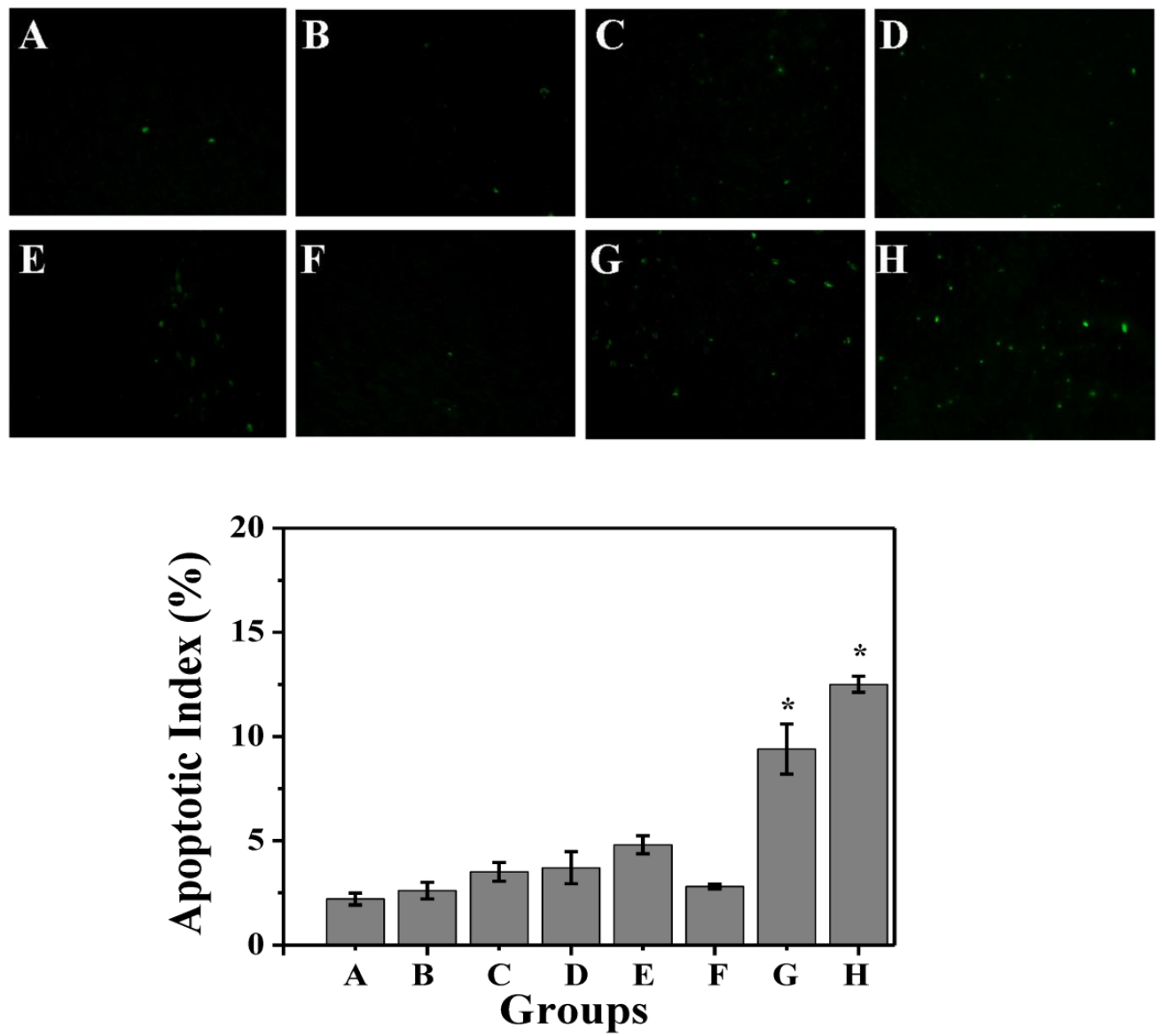

Figure 12. TUNEL immunofluorescent staining of tumors after NIR laser irradiation. Representative TUNEL immunofluorescent images and mean apoptotic index of A) NS, B) NS+laser, C) free DOX for 1 time, D) free DOX for 4 times, E) P-DOX, F) P-GNRs, G) P-GNRs+laser, and H) P-GNRs-DOX+laser. *P<0.01 by two-sample student's $t$-test. Images were acquired at $400 \times$ magnification.

\section{Conclusion}

In summary, we studied the chemo-physical properties and therapeutic effects of P-GNRs-DOX in vitro and in vivo. DOX release can be stimulated by the temperature rise of GNRs induced by NIR laser irradiation. Effective tumor ablation was observed after intravenous injection of P-GNRs-DOX followed by NIR laser irradiation, whereas DOX chemotherapy or P-GNRs photothermal treatment alone did not eliminate all tumors or prevent reoccurrence. Our results revealed that combined chemo- and photothermal co-therapy based on P-GNRs-DOX was superior to chemotherapy and photothermal therapy alone. Moreover, the dose of DOX in the P-GNRs-DOX treatment group was reduced by $50 \%$ which may be due to decreased side effects compared to the DOX group. Thus, the chemo-photothermal treatment based on polymersomes loaded with DOX and GNRs is a useful and effective strategy for both maximizing the therapeutic efficacy and minimizing the dosage-related side effects in the treatment of solid tumors. Future research will focus on the mechanism of the co-therapy of this photothermal and chemother- apy and active targeting of the P-GNRs-DOX by conjugation with tumor cell surface receptor ligands[49-51].

\section{Supplementary Material}

Fig.S1. http://www.thno.org/v05p0345s1.pdf

\section{Acknowledgements}

This work was financially supported by National Natural Science Foundation (NSFC31222023), and Distinguished Young Scholars of Sichuan University (2011SCU04B18). We thank LetPub for its linguistic assistance during the preparation of this manuscript.

\section{Competing Interests}

The authors have declared that no competing interest exists.

\section{References}

1. Choi W, Kim JY, Kang C, et al. Tumor regression in vivo by photothermal therapy based on gold-nanorod-loaded, functional nanocarriers. ACS Nano. 2011; 5: 1995-2003.

2. Cole JR, Mirin NA, Knight MW, et al. Photothermal efficiencies of nanoshells and nanorods for clinical therapeutic applications. J Phys Chem C. 2009; 113: 12090-4. 
3. Helmchen F, Denk W. Deep tissue two-photon micro-scopy. Nat Methods. 2005; 2: 932-40.

4. Dreaden EC, Mackey MA, Huang X, et al. Beating cancer in miltiple ways using nanogold. Chem Soc Rev. 2011; 40: 3391-404.

5. Nakamura T, Tamura A, Murotani H, et al. Large payloads of gold nanoparticles into the polyamine network core of stimuli-responsive PEGylayted nanogels for selective and noninvasive cancer photothermal therapy. Nanoscale. 2010; 2: 739-46.

6. Llevot A, Astruc D. Application of vectorized gold nanoparticles to the diagnosis and therapy of cancer. Chem Soc Rev. 2012; 41: 242-57.

7. Deng H, Zhong YQ, Du MH, et al. Self-assembly structure of gold nanoparticles for NIR photothermal therpy and X-ray computed tomography imaging. Theranostics. 2014; 4: 904-18.

8. Cho EC, Liu Y, Xia YN. A simple spectroscopic method for differentiating cellular uptakes of gold nanospheres and nanorods from their mixtures. Angew Chem Int Ed. 2010; 122: 2020-4

9. Srivatsan A, Jenkins SV, Jeon M, et al. Gold nanocage-photoshensitizer conjugated for dual-modal image-guided enhanced photodynamic therapy. Theranostic. 2014; 4: 163-74

10. Peng JR, Qi TT, Liao JF, et al. Mesoporous magnetic gold "nanoclusters" as theranostic carrier for chemo-photothermal co-therapy of breast cancer. Theranostics. 2014; 4: 678-92.

11. Chen HY, Zhang X, Dai SH, et al. Multifunctional gold nanostar conjugates for tumor imaging and combined photothermal and chemo-therapy. Theranostics. 2013; 3: 633-49.

12. Khlebtsov N, Bogatyrev V, Dykman L, et al. Analytical and theranostic applications of gold nanoparticles and multifunctional nanocomposites. Theranostics. 2013; 3: 167-80.

13. Liu HY, Chen D, Li LL, et al. Multifunctional gold nanoshells on silica nanorattles: a platform for the combination of photothermal therapy and chemotherapy with low systemic toxicity. Angew Chem Int Ed. 2011; 50: 891-5.

14. Ke HT, Wang JR, Tong S, et al. Gold nanoshelled liquid perfluorocarbon magnetic nanocapsules: a nanotheranostic platform for bimodal ultrasound/magnetic resonance imaging guide photothermal tumor ablation. Theranostics. 2014; 4: 12-23.

15. Yang J, Lee J, Kang J, et al. Smart drug-loaded polymer gold nanoshells for systemic and localized therapy of human epithelial cancer. Adv Mater. 2009; 21: 4339-42.

16. Matteini P, Ratto F, Rossi F, et al. Chitosan films doped with gold nanorods as laser-activable hybrid bioadhesives. Adv Mater. 2010; 22: 4313-6.

17. Chen NT, Tang KC, Chuang MF, et al. Enhanced plasmonic resonance energy transfer in mesoporous silica-encased gold nanorod for two-photon-activated photodynamic therapy. Theranostic. 2014; 4: 798-807.

18. Ke H, Wang J, Dai Z, et al. Biofunctional gold nanorod-loaded polymeric microcapsules for both contrast-enhanced ultrasound imaging and photothermal therapy. J Mater Chem. 2011; 21: 5561-4.

19. Takahashi $\mathrm{H}$, Niidome $\mathrm{Y}, \mathrm{Niidome} \mathrm{T}$, et al. Modification of gold nanorods using phosphatidycholine to reduce cytotoxicity. Langmuir. 2006; 22: 2-5.

20. Huang $X$, Peng $X$, Wang $Y$, et al. Reexamination of active and passive tumor targeting by using rod-shaped gold nanocrystals and covalently conjugated peptide ligands. ACS Nano. 2010; 4: 5887-96.

21. Alkilany AM, Shatanawi A, Kurtz T, et al. Toxicity and cellular uptake of gold nanorods in vascular endothelium and smooth muscles of isolated rat blood vessel: importance of surface modification. Small. 2012; 8: 1270-8.

22. Leonov AP, Zheng J, Clogston JD, et al. Detoxification of gold nanorods by treatment with polystyrenesulfonate. ACS Nano. 2008; 2: 2481-8.

23. Parab HJ, Chen HM, Lai TC, et al. Biosensing, cytotoxity, and cellular uptake studies of surface-modified gold nanorods. J Phys Chem C. 2009; 113: 7574-8.

24. Wei $\mathrm{Q}$, $\mathrm{Li} \mathrm{T}$, Wang GL, et al. $\mathrm{Fe}_{3} \mathrm{O}_{4}$ nanoparticles-loaded PEG-PLA polymeric vesicles as labels for ultrasensitive immunosensors. Biomaterials. 2010; 31: 7332-9.

25. Liu GY, Liu XS, Wang SS, et al. Biomimetic polymersomes as carriers for hydrophilic quantum dots. Langmuir. 2012; 28: 557-62.

26. Sanson C, Diou O, Thévenot J, et al. Doxorubic in loaded magnetic polymersomes: theranostic nanocarriers for MR imaging and magneto-chemotherapy. ACS Nano. 2011; 5: 1122-40.

27. Kita-Tokarczyk K, Grumelard J, Haefele T, et al. Block copolymer vesicles-using concepts from polymer chemistry to mimic biomembrane. Polymer. 2005; 46: 3540-63.

28. Christian DA, Cai S, Bowen DM, et al. Polymersomes carriers: from self-assembly to siRNA and protein therapeutics. Eur J Pharm Biopharm. 2009; 71: 463-74.

29. Levine DH, Ghoroghchian PP, Freudenberg J, et al. Polymersomes: a new multi-functional tool for cancer diagnosis and therapy. Methods. 2008; 46: $25-32$.

30. Fu SZ, Wang $\mathrm{XH}$, Guo $\mathrm{G}$, et al. Preparation and characterization of nano-hydroxyapatite/poly(E-caprolactone)-poly(ethylene glycol)-poly( $(\varepsilon$ caprolactone) composite fibers for tissue engineering. J Phys Chem C. 2010; 114: $18372-8$.

31. Upadhyay KK, Bhatt AN, Mishra AK, et al. The intracellular drug delivery and anti tumor activity of doxorubicin loaded poly ( $\mathrm{\gamma}$-benzyl L-glutamate)-b-hyaluronan polymersomes. Biomaterials. 2010; 31: 2882-92.

32. Ma M, Chen HR, Chen $Y$, et al. Au capped magnetic core/mesoporous silica shell nanoparticles for combined photothermo-/chemo-therapy and multimodal imaging. Biomaterials. 2012; 33: 989-98.
33. Xiao ZY, Ji CW, Shi JJ, et al. DNA self-assembly of targeted near-infrared-responsive gold nanoparticles for cancer thermo-chemotherapy. Angew Chem Int Ed. 2012; 51: 1-6.

34. Stüber W, Fink A, Bohn E. Controlled growth of monodisperse silica spheres in micron size range. J Colloid Interface Sci. 1968; 26: 62-9.

35. Gou ML, Zheng XL, Men K, et al. Self-assembled hydrophobic honokiol loaded MPEG-PCL diblock copolymer micelles. Pharm Res. 2009; 26: 2164-73.

36. Yang Q, Liao JF, Deng $X$, et al. Anti-tumor activity and safety evaluation of fisetin-loaded methoxy poly(ethylene glycol)-poly( $\varepsilon$-caprolactone) nanoparticles. J Biomed Nanotech. 2014; 10: 580-91.

37. Sau TK, Murphy CJ. Seeded high yield synthesis of short Au nanorods in aqueous solution. Langmuir. 2004; 20: 6414-20.

38. Vijayan K, Discher DE, Lal J, et al. Interaction of membrane-active peptides with thick, neutral, nonzwitterionic bilayers. J Phys Chem B. 2005; 109: 14356-64.

39. I. F. Uchegbu, S. P. Vyas, Non-ionic surfactant based vesicles (niosomes) in drug delivery. Int J Pharm. 1998; 172: 33-70.

40. Liao JF, Wang C, Wang YJ, et al. Recent advances in formation, properties, and application of polymersomes. Curr Pharm Design. 2012; 18: 3432-41.

41. Ayen WY, Kumar N. A systematic study on lyophilization process of polymersomes for long-term storage using doxorubicin-loaded (PEG) ${ }_{3}$-PLA nanopolymersomes. Eur J Pharm Sci. 2012; 46: 405-14.

42. Chen Y-S, Frey W, Kim S, et al. Enhanced thermal stability of silica-coated gold nanorods for photoacoustic imaging and image-guided therapy. Opt Express. 2010; 18: 8867-78.

43. Petrova H, Juste JP, Pastoriza-Santos I, et al. On the temperature stability of gold nanorods: comparison between thermal and ultrafast laser-induced heating. Phys Chem Chem Phys. 2006; 8: 814-21.

44. You J, Zhang GD, Li C. Exceptionally high payload of doxorubincin in hollow gold nanospheres for near-infrared light-triggered drug release. ACS Nano. 2010; 4: 1033-41.

45. Yavuz MS, Cheng YY, Chen JY, et al. Gold nanocages covered by smart polymers for controlled release with near-infrared light. Nat Mater. 2009; 8: 935-9.

46. Hribar $\mathrm{KC}$, Lee $\mathrm{MH}$, Lee $\mathrm{D}$, et al. Enhanced release of small molecules from near-infrared light responsive polymer-nanorod composites. ACS Nano. 2011; 5: $2948-56$

47. Lee SM, Kim HJ, Ha YJ, et al. Targeted chemo-photothermal treatments of rheumatiod arthritis using gold half-shell multifunctional nanoparticles. ACS Nano. 2013; 7: 50-7.

48. Kumar CSSR, Mohammad F. Magnetic nanomaterials for hyperthermia-based therapy and controlled drug delivery. Adv Drug Del Rev. 2011; 63: 789-808.

49. Zhu J, Huang H, Dong S, Ge L, et al. Progress in aptamer-mediated drug delivery vehicles for cancer targeting and its implications in addressing chemotherapeutic challenges. Theranostics. 2014; 4: 931-44.

50. Hondroulis E, Zhang R, Zhang C, et al. Immuno nanoparticles integrated electrical control of targeted cancer cell development using whole cell bioelectronic device. Theranostics. 2014; 4: 919-30.

51. Turker NS, Heidari P, Kucherlapati R, et al. An EGFR targeted PET imaging probe for the detection of colonic adenocarcinomas in the setting of colitis. Theranostics. 2014; 4: 893-903 